\title{
Single Crystals and Oxidation of $\mathrm{Cu}_{x} \mathrm{Mo}_{6} \mathrm{~S}_{8}$
}

\author{
By S. Tsunekawa*, H. Nakajima*, T. Miura* and T. Fukuda*
}

\begin{abstract}
Single Crystals of $\mathrm{Cu}_{x} \mathrm{Mo}_{6} \mathrm{~S}_{8}(1.4 \leq x \leq 1.7)$ are grown by the Bridgman method. SIMS, RBS, and Xray analyses reveal that the oxidation on the $\{100\}_{R}$ cleaved surfaces in air at $\sim 473 \mathrm{~K}\left(200^{\circ} \mathrm{C}\right)$ forms two layers, copper oxides ( $\sim 0.1 \mu \mathrm{m}$ deep) and "dilute zone" (a few $\mu \mathrm{m}$ deep) in order from the surface. Total variation of copper component in the bulk of $\mathrm{Cu}_{\sim 1.5} \mathrm{Mo}_{6} \mathrm{~S}_{8}$ crystals is $0.002 / \mathrm{h}$ in oxidation at $463 \mathrm{~K}$ $\left(190^{\circ} \mathrm{C}\right)$.
\end{abstract}

(Received June 28, 1988)

Keywords: Chevrel-phase compounds, single crystals, oxidation, channel structure, secondary ion mass spectroscopy, Rutherford backscattering spectrometry

\section{Introduction}

Crystal structure and physical properties, especially superconductivity, of numerous Chevrel-phase compounds have been examined and discussed ${ }^{(1)(2)}$, but their chemical properties have not been almost paid attention.

Copper Chevrel compounds $\mathrm{Cu}_{x} \mathrm{Mo}_{6} \mathrm{~S}_{8}$ is of the first kind: $\mathrm{Cu}$ concentration $x$ may vary continuously between the two limits $(1 \leq x \leq 4)^{(1)}$. These $\mathrm{Cu}$ ions can enter the chalcogen "channels" which are running in the direction of the rhombohedral axes ${ }^{(2)}$.

Recently we have observed by DTA and TG analyses, and X-ray diffractometry that $\mathrm{Cu}_{\sim 2} \mathrm{Mo}_{6} \mathrm{~S}_{8}$ powders change into $\mathrm{Cu}_{\sim 1} \mathrm{Mo}_{6} \mathrm{~S}_{8}$ by oxidation in atmosphere at high temperatures up to $573 \mathrm{~K}\left(300^{\circ} \mathrm{C}\right)^{(3)}$. It is interesting to investigate whether such a structural change is peculiar to powder samples or not.

The present paper reports on the preparation of $\mathrm{Cu}_{x} \mathrm{Mo}_{6} \mathrm{~S}_{8}(1.4 \leq x \leq 1.7)$ single crystals, the existence of copper oxides very near the crystal surface, and the reduction profiles of $\mathrm{Cu}$ ions near the surface and in the bulk, after heat treatment in air at $463-473 \mathrm{~K}\left(190-200^{\circ} \mathrm{C}\right)$.

\section{Experimental}

Single crystals of $\mathrm{Cu}_{x} \mathrm{Mo}_{6} \mathrm{~S}_{8}$ were grown by Bridgman technique using a high-temperature

* Institute for Materials Research, Tohoku University, Katahira, Sendai 980, Japan. and high-pressure furnace (DP-100MP, Kokusai Electric Co.) in the same manner as reported in the previous work ${ }^{(4)}$. First, the powder reagents of $\mathrm{Cu}(99.99 \%, 300$ mesh, Mitsuwa Chemical Co.), Mo (99.9\%, sintered up to 200 mesh in a vacuum, High Purity Chemetals Co.), and S (99.999\%, 200 mesh, Mitsuwa Chemical Co.) were mixed to be $x=1.8$ with a mixer (Model S-1, Tsutsui Rigaku Kikai Co.) for $1 \mathrm{~h}$, isostatically pressed, sealed in a Mo container $\left(20^{d \phi} \times 80^{h}\right)$, and then heated up to $1773 \mathrm{~K}\left(1500^{\circ} \mathrm{C}\right)$ for 12 h. Next, it was put into a high quality $\mathrm{Al}_{2} \mathrm{O}_{3}$ crucible (SSA-S, $16^{d \phi} \times 80^{h}$ ), heated up to 2123 $\mathrm{K}\left(1850^{\circ} \mathrm{C}\right)$ at the center of the crucible under $\mathrm{He}$ gas pressures of $2.94-3.43 \mathrm{MPa}(30-35$ $\left.\mathrm{kg} / \mathrm{cm}^{2}\right)$, and then lowered at the rate of 2 $\mathrm{mm} / \mathrm{h}$.

A boule with large grains was obtained (see Fig. 1). The X-ray powder analysis for the grains revealed that the concentration of $\mathrm{Cu}$ is $\sim 1.4$ near the top, $\sim 1.7$ near the bottom, and $\sim 1.5$ for the most part of the remains ${ }^{(5)}$. The dimensions of the $\{100\}_{R}$ cleaved surfaces were more than $5 \times 5 \mathrm{~mm}^{2}$, where the subfix $R$ means rhombohedral. The surfaces were polished very carefully by alumina abrasive ( 5 to $0.05 \mu \mathrm{m}$, Buehler Ltd.) until they showed no scratch under a metallurgical microscope (SZH-151, Olympus Optical Co.), because the crystal is brittle and the cleavage is strong.

Three samples were oxidized for 1,10 and $20 \mathrm{~h}$, respectively, at $463-473 \mathrm{~K}$, using an electric furnace with an air flow of $\sim 20 \mathrm{l} / \mathrm{h}$.

Distribution of oxygen and the other 


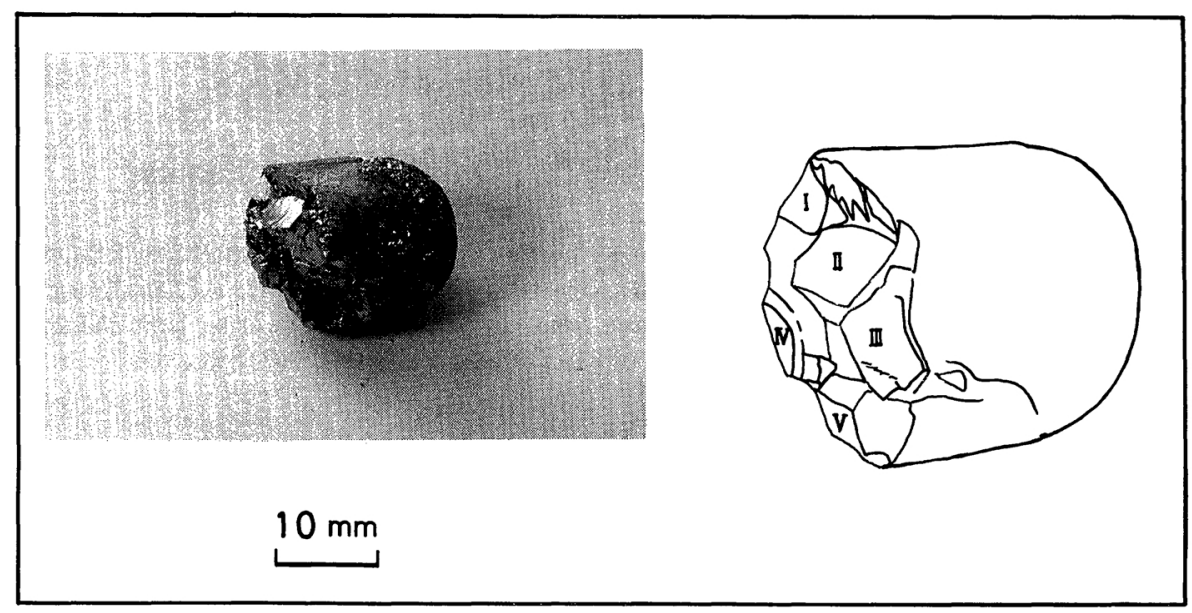

Fig. 1 Broken-out section of the Cu-Chevrel boule grown by the Bridgman method. Five large $\{100\}_{\mathrm{R}}$ cleaved surfaces are shown by Roman numerals.

elements, particularly copper, near the surfaces was investigated by SIMS (Secondary Ion Mass Spectroscopy), RBS (Rutherford Backscattering Spectrometry), and X-ray diffractometry.

As-polished and oxidized samples were analyzed by SIMS (IMA-3, Hitachi Ltd.) with primary ions $\mathrm{C}_{\mathrm{s}}^{+}(5 \mathrm{keV})^{\dagger}$. After the analysis, the depth of sputtered craters was measured by a depth profilometer to determine the sputtering rate. The composition of the other samples in deeper regions was measured by RBS (Dynamitron, Radiation Dynamics Ltd.) with a $\mathrm{He}^{+}$beam of $2.7 \mathrm{MeV}$.

The relation between the lattice spacing $d_{100}$ and the $\mathrm{Cu}$ component $x$ is given by Tovar et $a l .{ }^{(5)}$ as shown in Fig. 2. The value of $x$ was determined by comparing the value of $d_{100}$ with the five- and six-fold values of $d_{500}$ and $d_{600}$, respectively, obtained from the higher index reflections of the X-ray crystal diffraction $\left(\mathrm{CuK} \alpha_{1}\right.$ and $\alpha_{2}, 525 \mathrm{~W}$, Geigerflex 2027, Rigaku Corp.) on the $\{100\}_{R}$ surfaces, because the oxidation of single crystals changed only the $\mathrm{Cu}$ component in the bulk in the same manner as that of the powders ${ }^{(3)}$ as shown by SIMS and RBS measurements.

$$
1 \mathrm{eV}=1.6022 \times 10^{-19} \mathrm{~J}
$$

\section{Results and Discussion}

The values of $\mathrm{Cu}$ component $x$ determined by the X-ray crystal diffraction are listed in Table 1. The changes of $x$ in the samples C-2 and $\mathrm{C}-3$ suggest that the decrease of $\mathrm{Cu}$ concentration in the bulk is proportional to the oxidation time. The total variation of $\mathrm{Cu}$ component in the bulk is evaluated to be 0.0018 $0.0020 / \mathrm{h}$ at $463 \mathrm{~K}$.

The concentration-distribution profiles of four elements in the sample $\mathrm{C}$ - 1 obtained from SIMS measurement are shown in Fig. 3, where each profile illustrated by a narrow line represents a reference obtained for the aspolished $\{100\}_{\mathrm{R}}$ surface of another crystal $(x=1.46)$. Comparing the two profiles for each element, it is found that copper oxides exist in a narrow range of $0.15 \mu \mathrm{m}$ at maximum from the surface, because only copper and oxygen show significant deviations from the reference profiles which represent that both copper and oxygen are enriched very near the surface.

The results of RBS measurement for the aspolished C-2 and the oxidized C-3 samples are shown in Fig. 4(a) and (b), respectively. These are analyzed by the relation ${ }^{(6)}$,

$$
N_{\mathrm{i}}=\left(I_{\mathrm{i}} / S_{\mathrm{i}}\right)\left(S_{\mathrm{Mo}} / I_{\mathrm{Mo}}\right) N_{\mathrm{Mo}}
$$




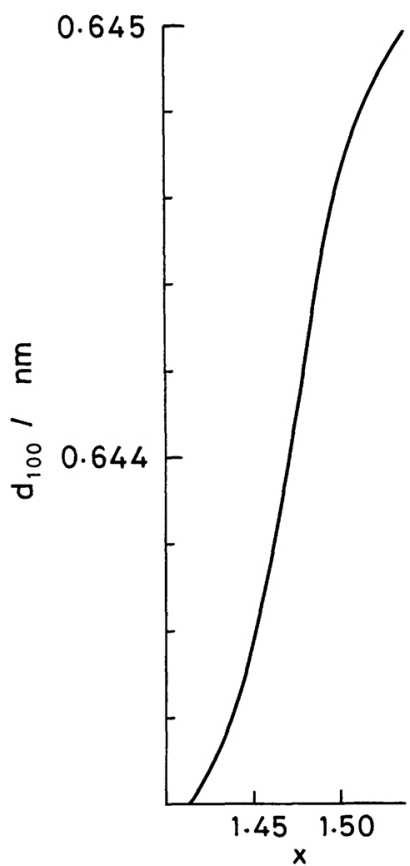

Fig. 2 Relation between $\mathrm{Cu}$ component $x$ and lattice spacing $d_{100}$ given by Tovar et al. ${ }^{(5)}$.

where $N_{\mathrm{i}}, I_{\mathrm{i}}$ and $S_{\mathrm{i}}$ mean the concentration, backscattering yield, and ion beam cross-section for $2.7 \mathrm{MeV}$, respectively, of the i-th element. Numerical values normalized by the Mo concentration $N_{\mathrm{Mo}}=6.00$ are listed in Table 2 . From the comparison of the values in Table 2 with those in Table 1, the followings are derived:

(i) $\mathrm{Cu}$ component $x$ in the as-polished C-2 sample shows no difference between the X-ray and RBS data, $x=1.51$ (1) and 1.52 .

(ii) $\mathrm{Cu}$ component $x$ of the oxidized C-3 sample shows a clear difference between them, $x=1.460(5)$ and $x=1.20$.

In order to explain these differences, the depth of the regions measured by the X-ray diffrac-

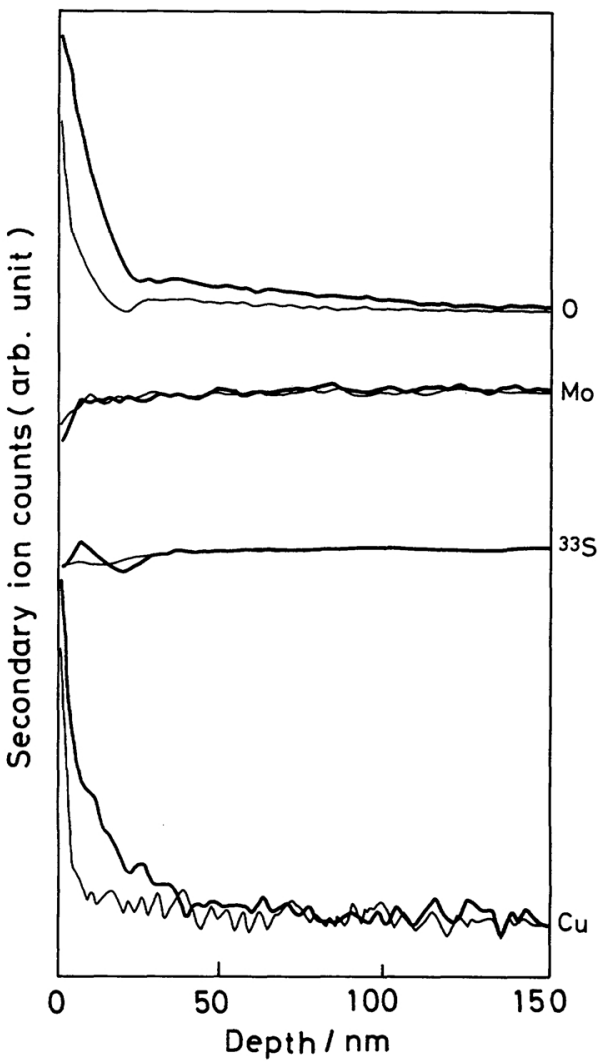

Fig. 3 Concentration-distribution profile of the elements on the $\{100\}_{\mathrm{R}}$ surfaces of $\mathrm{Cu}$-Chevrel single crystals by SIMS analysis. Oxidized sample (-), and as-polished sample as a reference (-).

tion with $\mathrm{CuK} \alpha$ and the $\mathrm{RBS}$ with $\mathrm{He}^{+}$is estimated.

Mass absorption coefficient $\mu / \rho$ for the Xrays is given by

$$
\mu / \rho=\sum_{\mathrm{i}}(\mu / \rho)_{\mathrm{i}} a_{\mathrm{i}} x_{\mathrm{i}} / \sum_{\mathrm{i}} a_{\mathrm{i}} x_{\mathrm{i}}
$$

where $(\mu / \rho)_{\mathrm{i}}, a_{\mathrm{i}}$ and $x_{\mathrm{i}}$ mean mass absorption coefficient $^{(7)}$, atomic weight, and chemical com-

Table $1 \mathrm{Cu}$ component $x$ in copper-Chevrel compounds estimated from the $x$ vs $d_{100}$ curve in Fig. 2. Numerical values in the parentheses represent errors.

\begin{tabular}{cccccc}
\hline \hline \multirow{2}{*}{ Samples } & \multicolumn{2}{c}{ As-polished } & \multicolumn{2}{c}{ After heat treatment } & Remarks \\
\cline { 2 - 5 } & $d_{100} / \mathrm{nm}$ & $x$ & $d_{100} / \mathrm{nm}$ & $x$ & \\
\hline $\mathrm{C}-1$ & - & - & $0.6436(2)$ & $1.45(1)$ & $473 \mathrm{~K}, 1 \mathrm{~h}$ \\
$\mathrm{C}-2$ & $0.64476(17)$ & $1.51(1)$ & $0.64446(16)$ & $1.49(1)$ & $463 \mathrm{~K}, 10 \mathrm{~h}$ \\
$\mathrm{C}-3$ & $0.64456(10)$ & $1.495(5)$ & $0.64375(11)$ & $1.460(5)$ & $463 \mathrm{~K}, 20 \mathrm{~h}$ \\
\hline \hline
\end{tabular}



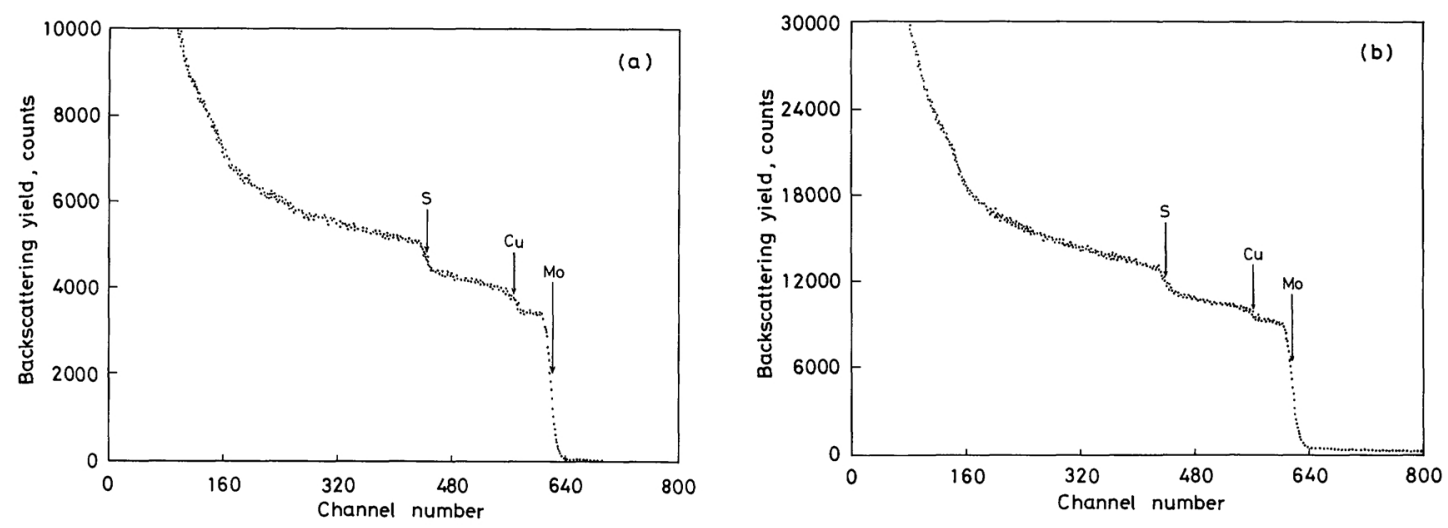

Fig. 4 RBS spectra with a $\mathrm{He}^{+}$beam of $2.7 \mathrm{MeV}$ for the $\{100\}_{\mathrm{R}}$ surfaces of $\mathrm{Cu}$-Chevrel single crystals. As-polished C-2 sample (a), and C-3 sample oxidized for $20 \mathrm{~h}$ at $463 \mathrm{~K}$ (b).

Table 2 Composition near the surface of copper-Chevrel crystals C-2 and C-3 shown in Table 1. Concentration of the i-th element $N_{\mathrm{i}}$ is obtained by applying of eq. (1) to RBS spectra shown in Fig. 4, and by normalizing with $N_{\mathrm{Mo}}=6.00$.

\begin{tabular}{lccccc}
\hline \hline \multirow{2}{*}{$\begin{array}{l}\text { Element } \\
\mathrm{i}\end{array}$} & $\begin{array}{c}S_{\mathrm{i}} \\
{\left[10^{-28} \mathrm{~m}^{2}\right]}\end{array}$ & \multicolumn{3}{c}{ As-polished C-2 } & \multicolumn{3}{c}{ Oxidized C-3 } \\
\cline { 3 - 6 } & & $I_{\mathrm{i}}$ & $N_{\mathrm{i}}$ & $I_{\mathrm{i}}$ & $N_{\mathrm{i}}$ \\
[counts] & & \multicolumn{3}{c}{ [counts] } & \\
\hline $\mathrm{Mo}$ & 1.2989 & 3330 & 6.00 & 8400 & 6.00 \\
$\mathrm{Cu}$ & 0.6166 & 400 & 1.52 & 800 & 1.20 \\
$\mathrm{~S}$ & 0.1835 & 630 & 8.04 & 1600 & 8.09 \\
\hline \hline
\end{tabular}

position of the i-th element, respectively. The coefficient $\mu / \rho$ of $\mathrm{Cu}_{1.5} \mathrm{Mo}_{6} \mathrm{~S}_{8}$ for the $\mathrm{X}$-ray of $\mathrm{CuK} \alpha$ is evaluated to be $130.6 \times 10^{-4} \mathrm{~m}^{2} / \mathrm{g}$ by eq. (2). The density is also given to be 5.80 $\mathrm{Mg} / \mathrm{m}^{3}$ from the lattice parameters reported previously $^{(5)}$. Thus, the total linear absorption coefficient $\mu$ is determined to be $758 \times 10^{2} \mathrm{~m}^{-1}$. Since the X-ray emergent intensity is given by $I=I_{0} \exp (-\mu t)$, the effective range $t$ is estimated by $\mu t=1$, i.e. $t=13.2 \mu \mathrm{m}$. On the other hand, the depth scale in RBS spectra with a $\mathrm{He}^{+}$incident beam of $2.7 \mathrm{MeV}, \Delta x$ is given by the relation ${ }^{(6)}$,

$$
\Delta x=\Delta E /\left[\frac{\mathrm{d} E}{\mathrm{~d} x}\right]
$$

where $\Delta E$ is the energy interval per one channel, and $d E / \mathrm{d} x$ is the stopping cross-section. Replacing $\Delta E=3.6 \times 10^{3} \mathrm{eV}$ and $\mathrm{d} E / \mathrm{d} x$ $=6.97 \times 10^{10} \mathrm{eV} \mathrm{m}^{-1}$ for $\mathrm{Cu}$ in $\mathrm{Cu}_{1.5} \mathrm{Mo}_{6} \mathrm{~S}_{8}$ into eq. (3), the depth scale $\Delta x$ is evaluated to be $\sim 5.2 \mathrm{~nm} /$ channel. The depth for $\mathrm{Cu}$ spectra is estimated to be $\sim 0.6 \mu \mathrm{m}$ corresponding to 120 channels in Fig. 4. Consequently, the difference of the $\mathrm{Cu}$ component obtained by $\mathrm{X}$-ray diffractometry and RBS is due to the difference of the depth measured by them. A tentative $\mathrm{Cu}$-concentration profile for $\mathrm{Cu}$ Chevrel crystals oxidized at $463 \mathrm{~K}$ is illustrated in Fig. 5. This schematic shows that the oxidized crystal consists of three regions, copper-oxide layer in $\sim 0.1 \mu \mathrm{m}$ thickness, "dilute zone" in a few $\mu \mathrm{m}$ thickness, and the bulk in order from the surface, which were detected by SIMS, RBS, and X-ray measurements, respectively. The dilute zone is named by reason of

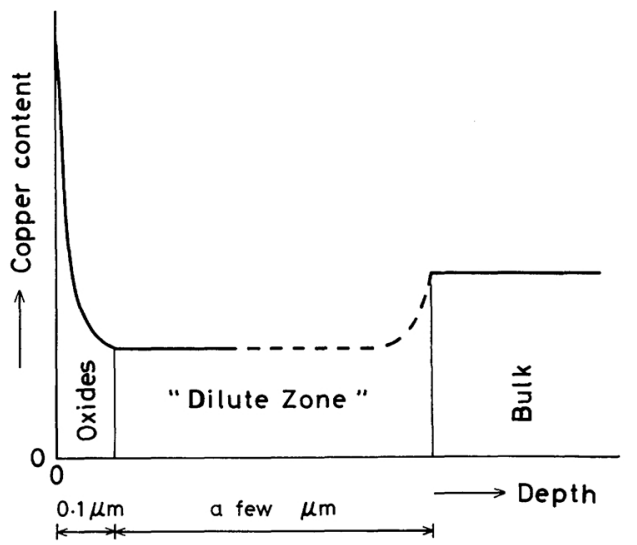

Fig. 5 Schematic profile of $\mathrm{Cu}$ content for $\mathrm{Cu}-\mathrm{Ch}$ evrel single crystals oxidized at $463 \mathrm{~K}$. 
the fact that the $\mathrm{Cu}$ component in the zone is lower than that in the bulk. It seems that this zone appears on account of the faster oxidation reaction than the $\mathrm{Cu}$ diffusion from the bulk, although the diffusion is thought to be most rapid for the $\{100\}_{R}$ cleaved surfaces, which are normal to the chalcogen channels. The fact that copper oxides are not detected in the crystals by the X-ray diffraction as well as in the powders ${ }^{(3)}$ suggests strongly that the oxides are amorphous.

\section{Conclusion}

The oxidation on the cleaved surface in copper-Chevrel crystals was very similar to that in the powders and offered further information:

(i) Only copper diffuses towards the surface and forms amorphous copper oxides on the surface. The copper-oxide layer is $\sim 0.1$ $\mu$ m thick.

(ii) There exists a "dilute zone" between the oxide layer and the bulk. The zone is a few $\mu$ m thick.

(iii) The reduction of copper component from the bulk is $0.002 / \mathrm{h}$ in oxidizing at $463 \mathrm{~K}$.

It is attractive to know the accurate dimension of the dilute zone and its temperaturedependence. Although it is difficult to directly determine them because of the lack of an adequate detector for a region of a few $\mu \mathrm{m}$ in depth, it may be solved by measuring the oxidation reaction and diffusion constants.

It is also interesting to examine whether an "enriched zone" is formed between the diminishing oxide layer and the bulk by annealing in a hydrogen-gas flow, since the reduction reaction might occur in copper-Chevrel single crystals as well as in the powders ${ }^{(3)}$.

\section{Acknowledgement}

The authors wish to thank Dr. M. Kitada of Central Research Laboratory in Hitachi Ltd. for his support in SIMS measurement.

\section{REFERENCES}

(1) Ø. Fisher: Appl. Phys., 16 (1978), 1.

(2) K. Yvon: Bonding and Relationships between Structure and Physical Properties in Chevrel-Phase Compounds $M_{x} M_{6} X_{8}(M=$ metal, $X=S, S e, T e)$, Current Topics in Materials Science Vol. 3, Ed. by E. Kaldis, North-Holland, Amsterdam, (1979), p. 63.

(3) H. Takei, S. Hosoya, S. Tsunekawa, M. Kikuchi and T. Kobayashi: Mat. Res. Bull., 21 (1986), 713.

(4) H. Takei, T. Takahashi and T. Miura: Jpn. J. Appl. Phys., 23 (1984), 420.

(5) M. Tovar, L. E. Delong, D. C. Johnston and M. B. Maple: Solid State Commun., 30 (1979), 551.

(6) Backscattering Spectrometry, Ed. by W. K. Chu, J. W. Mayer and M. A. Nicolet, Academic Press, New York, (1978), p. 76.

(7) International Tables for X-ray Crystallography, Vol. III, Physical and Chemical Tables, Kynoch Press, Birmingham (1962), p. 162. 